\title{
Stroke awareness in Brazil: what information about stroke is essential?
}

\author{
Conhecimento leigo sobre AVC no Brasil: que informação sobre AVC é essencial? \\ Octávio Marques Pontes-Neto
}

Departamento de Neurociências e Ciências do Comportamento,

Faculdade de Medicina de Ribeirão Preto, Universidade de São Paulo,

Ribeirao Preto SP, Brazil.

Correspondence:

Octávio Marques Pontes-Neto, Hospital das Clínicas, Faculdade de Medicina de Ribeirão Preto:

Av. dos Bandeirantes, $3.900 / 4^{\circ}$ andar / sala 438; 14049-900

Riberão Preto SP, Brasil;

E-mail: opontesneto@fmrp.usp.br

Conflict of interest:

The author is currently the President of the Brazilian Stroke Network, a non-governmental organization (NGO) devoted to promote and improve global care of stroke patients throughout the country and directly involved on the organization of stroke awareness campaigns in Brazil around the "World Stroke Day". No financial incentives of any sort come from this position.

Received 23 September 2014 Accepted 30 September 2014

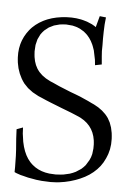
troke has been the leading cause of death and functional incapacity for decades in Brazil, with a major impact on public health ${ }^{1}$. Several factors may have contributed to this inconvenient reality: the delayed epidemiologic transition from infectious diseases to non-transmittable diseases in Brazil which occurred in the 1960s; ageing of the population and its multiethnic background; poor control of cerebrovascular risk factors; low availability to scientific proven treatments like intravenous thrombolysis and stroke units; low priority to stroke training for health care professionals; and poor awareness about stroke by the population ${ }^{2,3}$.

After years of struggle and resilience by the Brazilian Cerebrovascular Diseases Society, the Brazilian Academy of Neurology, in 2012, the Brazilian Ministry of Health published the National Stroke Policy Act, finally setting the battle against stroke as a national priority ${ }^{4}$. Since then, major steps have been gradually implemented to improve stroke care in the Country, including: reimbursement for stroke thrombolysis; improved financial incentives for stroke care within certified stroke units and stroke centers; training for healthcare professionals together with medical societies; establishment of the "Line of Stroke Care" which defined stroke as a priority for primary/secondary prevention, pre-hospital care, acute care and rehabilitation according to local demand and resources ${ }^{4}$.

Lack of information about stroke within the population was alarming in Brazil ${ }^{3}$. More recently some progress has been made. As a first step, the acronym "AVC" was adopted as the unified term to name stroke in the country ${ }^{5}$. Stroke awareness campaigns around the "World Stroke day" (February, 29 ) have been organized by the Brazilian Stroke Society, Brazilian Stroke Network and Brazilian Academy of Neurology and brought substantial media exposure to the condition. This effort has been supported by the Brazilian Ministry of Health and was ultimately recognized with an award of "best stroke awareness campaign" in 2012 by the World Stroke Organization. Nevertheless, the long-term impact of these broad interventions in Brazil is still unknown and their content, focus and planning would definitely benefit from an evidence-based approach to evaluate their impact on acute stroke care $^{6}$.

In this issue of Arquivos de Neuro-Psiquiatria, Panício et al. report an cross-sectional study that addressed the knowledge about stroke warning signs and therapeutic time window for stroke thrombolysis among patients with acute ischemic and hemorrhagic stroke admitted to the emergency department of a tertiary public hospital in Sao Paulo, Brazil ${ }^{7}$. Although approximately two thirds of stroke patients showed some knowledge of stroke warning signs, only $7.8 \%$ patients were aware of the critical importance of early arrival for adequate stroke treatment. Interestingly, knowledge about stroke symptoms was not a predictor of early arrival in this hospital-based series. Instead, stroke severity was the only independent predictor to early hospital arrival, as previously reported in another study about hemorrhagic stroke in Sao Paulo city ${ }^{8}$. The authors appropriately discuss that limited knowledge about the therapeutic time window for the treatment of acute ischemic stroke and lack of access to emergency medical services could be possible explanations for these findings. Alternative explanations may come from the small sample size of the study, a single-center design and from the local characteristics of its scenario. Indeed, the study may be unpowered to detect a 
small effect of knowledge about stroke. Patients with unknown time of onset of symptoms were included in the main analyses, which also combined patients ischemic and hemorrhagic stroke. After restricting the analyses to patients with ischemic stroke and a known time of onset authors report that the results have not changed substantially. Nevertheless, further studies with larger sample sizes would certainly be able to identify additional independent predictors of early arrival. More concerning, patients with prior stroke were not more likely to know about stroke signs and symptoms.

Given the great variability of pre-hospital emergency services and scenarios in Brazil, we cannot automatically extrapolate these results to other cities of the country.
Nevertheless, this interesting study raises a very important red flag: we still have a lot of work to do! Despite the fact that education about stroke was included as a crucial element of the National Stroke Policy Act, the number of health care professionals with formal stroke training is still very restricted. We also need to test and improve the efficacy and effectiveness of our population-based stroke awareness interventions. In parallel to improving health resources (stroke units and stroke centers), more effective information needs to be delivered to patients, their families and to first responders, with major attention to the organization and flow of the local stroke systems of care. That is the only way towards the goal that every stroke patient has the information he or she needs to get access to adequate stroke care.

\section{References}

1. Mansur AP, Souza MFM, Favarato D, Avakian SD, Machado CLA, Aldrigui JM et al. Stroke and ischemic heart disease mortality trends in Brazil from 1979 to 1996. Neuroepidemiology. 2003;22(3):179-83. http://dx.doi.org/10.1159/000069893

2. Lotufo PA. Stroke in Brazil: a neglected disease. Sao Paulo Med J. 2005;123(1):3-4. http://dx.doi.org/10.1590/s1516-31802005000100001

3. Pontes-Neto OM, Silva GS, Feitosa MR, Figueiredo NL, Fiorot JA Jr, Rocha TN et al. Stroke awareness in Brazil: alarming results in a community-based study. Stroke. 2008;39(2):292-6. http://dx.doi.org/ 10.1161/strokeaha.107.493908

4. Martins SC, Pontes-Neto OM, Alves CV, Freitas GR, Oliveira Filho J, Tosta ED et al. Past, present, and future of stroke in middle-income countries: the Brazilian experience. Int J Stroke. 2013;8(Suppl A100):106-11. http://dx.doi.org/10.1111/ijs.12062
5. Gagliardi R. Acidente vascular cerebral ou acidente vascular encefálico? Qual a melhor nomenclatura? [carta ao editor]. Rev Neurocienc. 2010;18(2):131-2. http://dx.doi.org/10.4181/RNC.2010.1802.02p

6. Payne GH, Fang J, Fogle CC, Oser CS, Wigand DA, Theisen $V$ et al. Stroke awareness: surveillance, educational campaigns, and public health practice. J Public Health Manag Pract. 2010;16(4):345-58. http://dx.doi.org/10.1097/phh.0b013e3181c8cb79

7. Panício MI, Mateus L, Ricarte IR, Figueiredo MM, Fukuda TG, Seixas JC et al. The Influence of Patient's Knowledge about Stroke in Brazil: a cross sectional study. Arq Neuropsiquiatr. 2014;72(12):938-941.

8. Valiente RA, Miranda-Alves MA, Silva GS, Gomes DL, Brucki SM, Rocha MS, Massaro AR. Clinical features associated with early hospital arrival after acute intracerebral hemorrhage: challenges for new trials. Cerebrovasc Dis. 2008;26(4):404-8. http://dx.doi.org/10.1159/000151681 